\title{
NVP-BKM120 potentiates apoptosis in tumor necrosis factor-related apoptosis-inducing ligand-resistant glioma cell lines via upregulation of Noxa and death receptor 5
}

\author{
KIMBERLY A. FOSTER ${ }^{1,2}$, ESTHER P. JANE ${ }^{1,2}$, DANIEL R. PREMKUMAR ${ }^{1,2}$ \\ ALEJANDRO MORALES $^{2}$ and IAN F. POLLACK ${ }^{1-3}$ \\ ${ }^{1}$ Department of Neurosurgery, ${ }^{2}$ University of Pittsburgh School of Medicine, \\ ${ }^{3}$ University of Pittsburgh Cancer Institute Brain Tumor Center, Pittsburgh, PA, USA
}

Received March 9, 2015; Accepted April 15, 2015

DOI: 10.3892/ijo.2015.3035

\begin{abstract}
We previously observed that glioma cells are differentially sensitive to TRAIL-induced toxicity. Based on our observation that TRAIL-resistant glioma cell lines typically exhibited high levels of Akt activation, we hypothesized that inhibition of Akt signaling using the PI3 kinase inhibitor NVP-BKM120 could promote TRAIL-induced apoptosis in gliomas. We assessed this combination in established and primary cultured glioma cells. Combination treatment led to significant cellular death when compared to either drug alone, but had no effect in normal human astrocytes, and demonstrated activation of the caspase cascade. This enhanced apoptosis appears dependent upon the loss of mitochondrial membrane potential and the release of Smac/DIABLO, AIF and cytochrome $\mathrm{c}$ into the cytosol. The upregulation of Noxa and sequestration of Mcl-1 by Noxa were important factors for cell death. Knockdown of Noxa abrogated apoptosis and suggested dependency on Noxa in combination-induced apoptosis. BKM120 upregulated cell surface expression of death receptor 5 (DR5), but did not increase levels of the other major TRAIL receptor, death receptor 4 (DR4). This study demonstrates that antagonizing apoptosis-resistance pathways, such as the PI3/Akt pathway, in combination with death receptor activation, may induce cell death in TRAIL-resistant glioma.
\end{abstract}

\section{Introduction}

Malignant glioma is an aggressive brain tumor that responds poorly to conventional treatment modalities (1-3). Gliomas demonstrate multiple modes of resistance and single-agent therapy has proven ineffective in treatment of malignant

Correspondence to: Dr Kimberly A. Foster, Department of Neurosurgery, Children's Hospital of Pittsburgh, 4401 Penn Ave., Pittsburgh, PA 15224, USA

E-mail: fosterka@upmc.edu

Key words: glioma, BKM120, TRAIL, apoptosis, Noxa glioma $(4,5)$. While the underlying basis for resistance to apoptosis is not fully understood $(6,7)$, recent discoveries as to the pathogenesis of glioblastoma have led to the development of rationally-designed, targeted therapies aimed at disrupting key signaling pathways.

Tumor necrosis factor-related apoptosis inducing ligand (TRAIL), a member of the TNF family, is a potential cancer agent due to its tumor-specific induction of apoptosis and human recombinant TRAIL is being tested in clinical trials for various cancer types (8-12). TRAIL initiates apoptosis by binding one of two main receptors, death receptor 4 and 5 (DR4 and DR5, respectively), which signal via an adaptor intermediate molecule that promotes formation of a deathinducing signaling cascade (DISC), and ultimately activation of caspase-8 and caspase-3 (13). While most human cancer cell lines express death receptors for Apo2L/TRAIL, many cancer types have proven resistant to TRAIL-induced cellular death (14-16). We, among others, have shown that many malignant gliomas are also TRAIL resistant, despite expression of TRAIL receptors (17-19) and aberrance in the NF- $\kappa \mathrm{B}$, protein kinase $\mathrm{C}, \mathrm{Bcl}-2$ and Akt pathways have all been implicated in TRAIL resistance in glioma (19-21). In particular, Akt pathway activation, which can occur secondary to PTEN deletion and/or PIK3CA mutations, is common in malignant glioma (22).

NVP-BKM120 is a highly selective pan-class I phosphatidylinositol-3 kinase (PI3K) inhibitor (23), shown to effectively induce apoptosis in tumor cell lines and animal models of cancer at clinically achievable doses (24-26), and a preliminary clinical trial suggests this agent is well-tolerated (27). A recent study demonstrated effective, synergistic induction of apoptosis in lung cancer cell lines when cells were co-treated with BKM-120 and TRAIL (28). To date, it has not been reported whether BKM120 can sensitize TRAIL-resistant malignant glioma cell lines to apoptosis. We previously observed that TRAIL-resistant glioma cell lines often exhibited high levels of Akt activation (Fig. 1) and, thus, we hypothesized that Akt pathway inhibition via the PI3 kinase inhibitor BKM120 could work with TRAIL to promote cell death in human glioma.

Herein, we show the combination of BKM120 and TRAIL in glioblastoma is effective in promoting cellular death and demonstrate that the effectiveness of this combination is likely 
contingent on the upregulation of the pro-apoptotic protein Noxa and the death receptor DR5.

\section{Materials and methods}

Cell lines. Two TRAIL-resistant cell lines were utilized (U87 and LNZ308). U87 was obtained from American Type Culture Collection (Manasas, VA, USA) and LNZ308 was kindly provided by Dr Nicolas de Tribolet (Switzerland). We obtained primary GBM cells from Conversant Biologics (Huntsville, AL, USA). Normal human astrocytes (HA) and media were obtained from ScienCell Research Laboratories (Carlsbad, CA, USA). Cell culture conditions of these cell lines were as previously described $(29,30)$.

Reagents and antibodies. Soluble human recombinant SuperKillerTRAIL (referred to as TRAIL in this study) was purchased from Enzo Biochemicals (Enzo Life Sciences, Farmingdale, NY, USA). NVP-BKM120 was purchased from Chemie Tek (Indianapolis, IN, USA). Caspase inhibitors (z-VAD-fmk, z-IETD-fmk, z-DEVD-fmk, and z-LEHD-fmk) were purchased from R\&D Systems (Minneapolis, MN, USA). The following antibodies were used: Mcl-1 (\#4572), cytochrome c (\#4280), cleaved poly-ADP-ribose polymerase (PARP, \#9546), cleaved caspase-3 (\#9664), cleaved caspase-8 (\#9496), cleaved caspase-9 (\#9501), Smac/DIABLO (\#2954), pAKT (\#5106), AKT (\#2920), pS6kinase (\#5364), pBAD (\#9105), BIM (\#2819), Bcl-2 (\#2872), Bcl-xL (\#2764), surviving (\#2808), XIAP (\#2042), DcR1 (\#4756) and $\beta$-actin (\#4970) were from Cell Signaling Technology (Beverly, MA, USA). Noxa (sc-26917) and apoptosis-inducing factor (AIF; sc-5586) were from Santa Cruz Biotechnology (Santa Cruz, CA, USA). DR4 (\#IMG-141A) and DR5 (\#IMG-122A) were from Imgenex (San Diego, CA, USA).

Annexin $V$ apoptosis assay. Apoptosis was evaluated using a fluorescent Annexin V/propidium iodide (PI) assay kit (Invitrogen, Carlsbad, CA, USA) as described previously $(29,30)$. Cells were treated with or without inhibitors for various intervals, harvested, and pelleted by centrifugation (1,000 rpm for $5 \mathrm{~min}$ ); washed in ice-cold phosphate-buffered saline (PBS); and re-suspended in the Annexin V-fluorescein isothiocyanate/PI reagent in the dark for $15 \mathrm{~min}$ before flow cytometric analysis using a FACSCalibur flow cytometer (BD Biosciences, San Jose, CA, USA).

DiOC6 labeling and detection of mitochondrial membrane depolarization. Mitochondrial membrane depolarization was measured as described previously $(29,30)$. Nonadherent cells were collected, and attached cells were trypsinized and resuspended in phosphate-buffered saline (PBS). Cells were loaded with $50 \mathrm{nM} \mathrm{3',3'-dihexyloxacarbo-cyanine} \mathrm{iodide} \mathrm{(DiOC6;}$ Invitrogen), which accumulates in intact mitochondria, at $37^{\circ} \mathrm{C}$ for $15 \mathrm{~min}$. Cells were then spun at 3,000 x g, rinsed with PBS, and resuspended. Fluorescence intensity was detected by flow cytometry and analyzed with CellQuest (BD Biosciences) and FlowJo (Tree Star, Inc., Ashland, OR, USA) analysis software.

Immunoprecipitation and western blot analysis. Western blot and immunoprecipitation were performed as previously

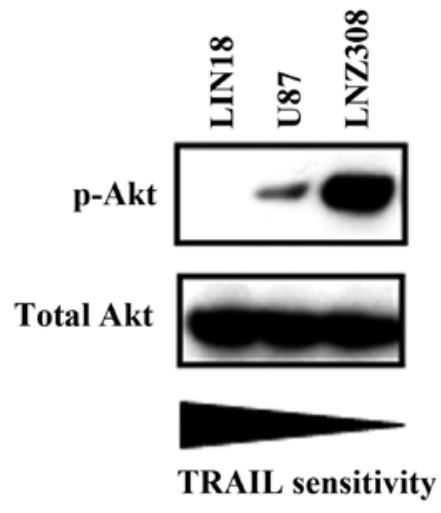

Figure 1. TRAIL-resistant glioma cell lines exhibit high levels of Akt activation. Untreated LN18, LNZ308 and U87 cell lines were examined and cell extracts were subjected to western blot analysis with the indicated antibody.

described (18). Cells were washed in ice-cold PBS and lysed in buffer containing $30 \mathrm{mM}$ HEPES, $10 \%$ glycerol, $1 \%$ Triton $\mathrm{X}-100,100 \mathrm{mM} \mathrm{NaCl}, 10 \mathrm{mM} \mathrm{MgCl}$, $5 \mathrm{mM}$ EDTA, $2 \mathrm{mM}$ $\mathrm{Na}_{3} \mathrm{VO}_{4}, 2 \mathrm{mM} \beta$-glycerophosphate, $1 \mathrm{mM}$ phenylmethylsulfonyl fluoride, $1 \mathrm{mM}$ 4-(2-aminoethyl) benzenesulfonyl fluoride, $0.8 \mu \mathrm{M}$ aprotinin, $50 \mu \mathrm{M}$ bestatin, $15 \mu \mathrm{M}$ E-64, $20 \mu \mathrm{M}$ leupeptin, and $10 \mu \mathrm{M}$ pepstatin A for $15 \mathrm{~min}$ on ice. Samples were centrifuged at $12,000 \mathrm{x}$ g for $15 \mathrm{~min}$, supernatants were isolated, and protein was quantified using protein assay reagent (Pierce Chemical, Rockford, IL, USA). Equal amounts of protein were separated by SDS-PAGE and electrotransferred onto a nylon membrane (Invitrogen). Nonspecific antibody binding was blocked by incubation of the membranes with $4 \%$ bovine serum albumin in Tris-buffered saline (TBS)/ Tween-20 (0.1\%). The membranes were incubated with primary antibody overnight at $4^{\circ} \mathrm{C}$, washed in TBS/Tween-20, and incubated with a 1:2000 dilution of horseradish peroxidaseconjugated secondary antibody in TBS/Tween-20 at room temperature for $1 \mathrm{~h}$. Proteins were visualized by western blot chemiluminescence reagent (Cell Signaling). Where indicated, the membranes were re-probed with antibodies against $\beta$-actin to ensure equal loading and transfer of proteins.

For immunoprecipitation, cell extracts were prepared by lysing $5 \times 10^{6}$ cells on ice for $30 \mathrm{~min}$ in CHAPS lysis buffer (10 mM HEPES, pH 7.4, 150 mM NaCl, 1\% CHAPS, protease, phosphatase inhibitors). Lysates were clarified by centrifugation, and equal amounts of protein extracts were incubated overnight with primary antibody. Dynabeads Protein G (Invitrogen) was added for $2 \mathrm{~h}$, followed by magnetic separation of the immunoprecipitated fraction; western blot analysis was conducted as outlined already herein. Scanning densitometry was performed using acquisition into Adobe Photoshop (Adobe Systems, Inc., San Jose, CA, USA) followed by image analysis (Un-Scan-It gel, version 6.1; Silk Scientific, Orem, UT, USA).

Subcellular fractionation. Cells were treated with or without inhibitors, and cytosolic proteins were fractionated as described previously (29). Cells were resuspended in lysis buffer containing $0.025 \%$ digitonin, sucrose $(250 \mathrm{mM})$, HEPES (20 mM, pH 7.4), magnesium chloride (5 mM), potassium chloride $(10 \mathrm{mM})$, EDTA $(1 \mathrm{mM})$, phenylmethylsulfonyl 
A

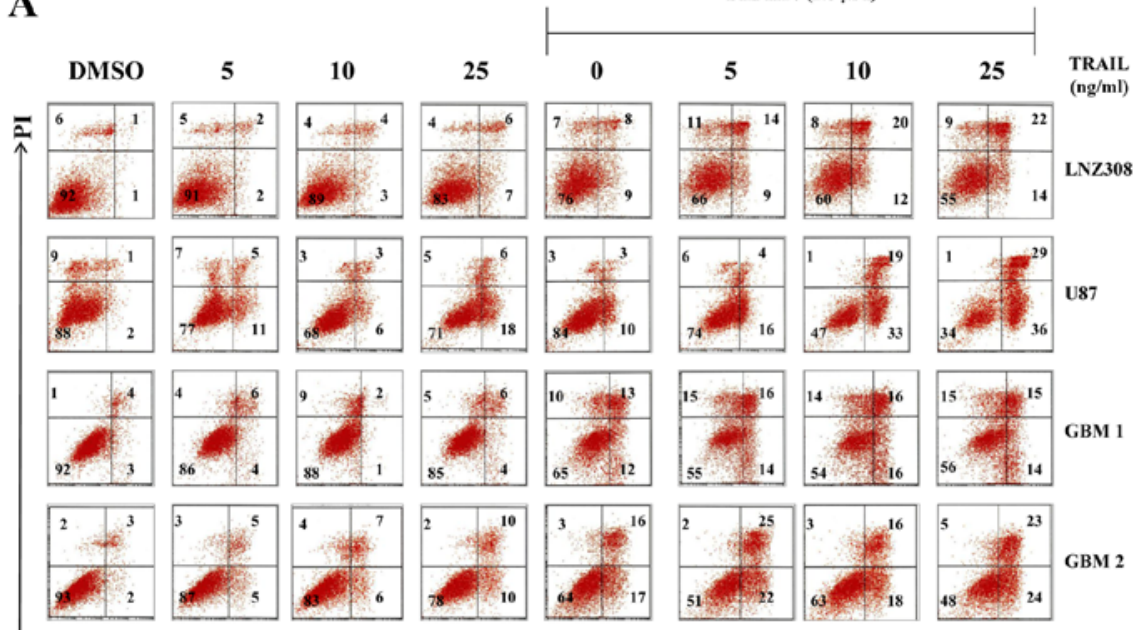

Annexin V-FITC
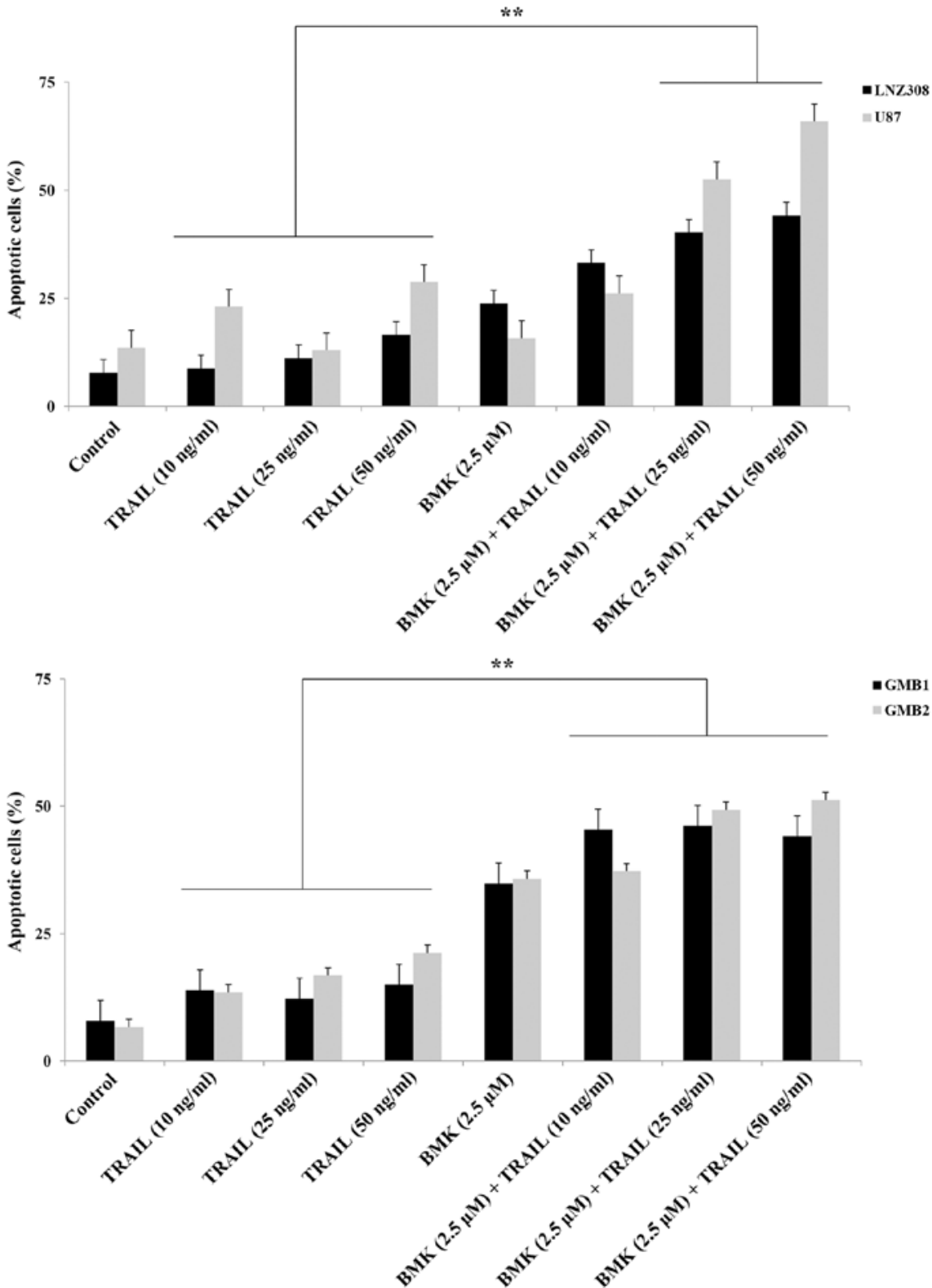

Figure 2. Combination treatment of BKM120 and TRAIL induces apoptosis in TRAIL-resistant glioma lines but not human astrocytes. (A) LNZ308 and U87 cell lines and primary cultures established from 2 glioblastoma (GBM) patient samples (GBM 1 and GBM 2) were treated as shown for $24 \mathrm{~h}$ and frequency of apoptotic cells was determined by cell surface Annexin V binding assay. The histograms are representative of one of at least three different experiments. Bar graphs are representative of three independent experiments. Standard deviation was $<5 \%$ and error bars are shown. ${ }^{* *} \mathrm{p}<0.05$. 

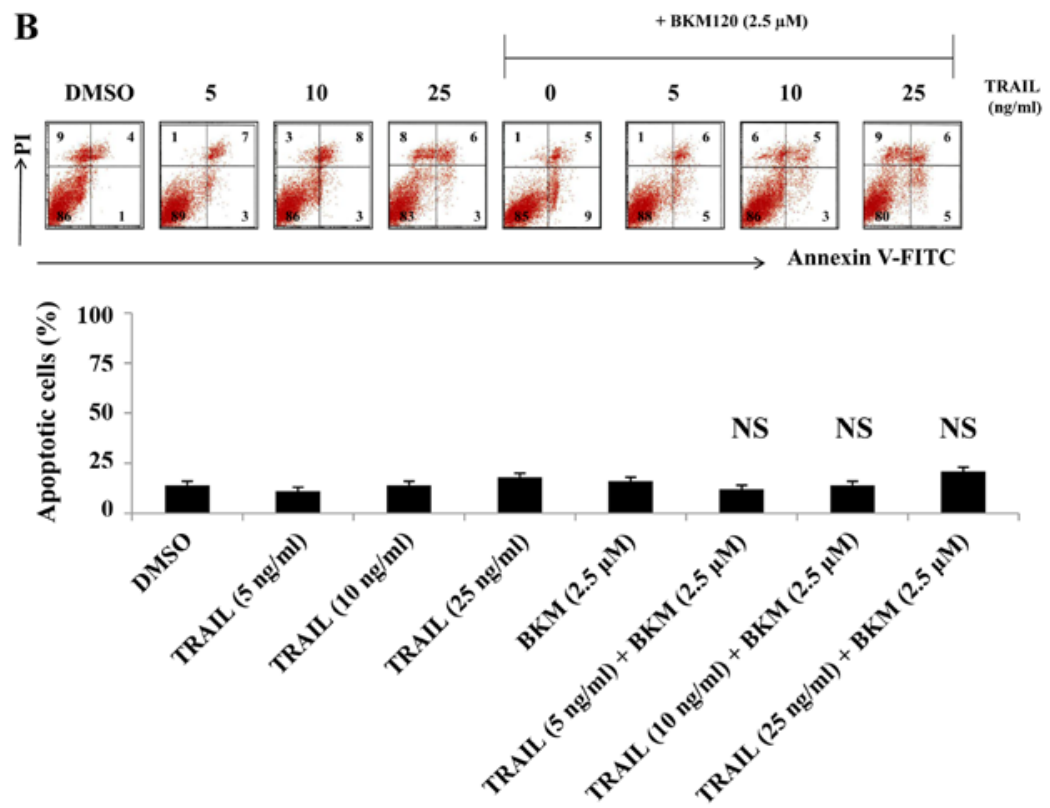

Figure 2. Continued. Combination treatment of BKM120 and TRAIL induces apoptosis in TRAIL-resistant glioma lines but not human astrocytes. (B) Normal human astrocytes were exposed to BKM120 or TRAIL or the combination of both for $24 \mathrm{~h}$ and frequency of apoptotic cells was determined by Annexin V binding assay. Standard deviation was $<5 \%$ and error bars are shown. NS, no statistically significant difference between treatment and control.

fluoride $(1 \mathrm{mM}), 10 \mu \mathrm{g} / \mathrm{ml}$ aprotinin, and $10 \mu \mathrm{g} / \mathrm{ml}$ leupeptin. After $10 \mathrm{~min}$ of incubation at $4^{\circ} \mathrm{C}$, cells were centrifuged ( $2 \mathrm{~min}$ at $13,000 \mathrm{x} \mathrm{g}$ ), and the supernatant (cytosolic fraction) was removed and frozen at $-80^{\circ} \mathrm{C}$ for subsequent use.

Transient transfection. Transient transfection was performed as previously described (18). Optimal 29mer-pRS-small hairpin (sh) RNA constructs were obtained from Origene (Rockville, MD). Sequences specific for human Noxa (GGA GGT GCT ACA CAA TGT GGC GTC GGC AC), Mcl-1 (ACC TAG AAG GTG GCA TCA GGA ATG TGC TG) and control sequences (GCA CTA CCA GAG CTA ACT CAG ATA GTA CT) (nontarget shRNA) were used for this study. Glioma cells were seeded in six-well plates and allowed to reach $70 \%$ confluence. Transfection of targeting or control shRNA was performed using FuGENE6 per the manufacturer's recommendations (Roche Applied Science, Indianapolis, IN, USA). One microgram of Mcl-1 or Noxa or nontargeting shRNA in $100 \mu \mathrm{l}$ of Opti-MEM medium was mixed with $2 \mu \mathrm{l}$ of FuGENE6 and incubated at room temperature for $20 \mathrm{~min}$, followed by the addition of complete medium to make the total volume up to $2 \mathrm{ml}$. After $48 \mathrm{~h}$, media were changed and cells were incubated with inhibitors or vehicle for $24 \mathrm{~h}$. Assessment of cell viability (Annexin V binding) was carried out as described (18).

Flow cytometry of death receptors. Cells were analyzed for surface expression of DR4 and DR5 by indirect staining with anti-human DR4 and DR5 (Imgenex), followed by FITCconjugated IgG. Briefly, cells $\left(1 \times 10^{6}\right)$ were stained with $300 \mu 1$ PBS containing saturating amounts of anti-DR4 and anti-DR5 overnight at $4^{\circ} \mathrm{C}$. After incubation, cells were washed with PBS and subjected to secondary antibody ( $\operatorname{IgG}$ ) for $1 \mathrm{~h}$ at room temperature. After washing, expression of death receptors were subjected to flow cytometric analysis using a FACSCalibur flow cytometer (BD Biosciences).
Statistical analysis. Unless otherwise indicated, data are expressed as mean \pm SD for at least three separate experiments performed in triplicate. The significance of differences between experimental conditions was determined using a twotailed Student's t-test. Differences were considered significant at P-values $\leq 0.05$.

\section{Results}

Combination treatment with BKM120 and TRAIL induces apoptosis in TRAIL-resistant glioma lines but not human astrocytes. To quantitatively assess the effects of this combination, LNZ308 and U87 cells were subjected to an Annexin V/PI analysis. Single agent treatment resulted in modest Annexin labeling, while co-treatment enhanced Annexin V/PI positive labeling. To demonstrate that sensitivity to this combination was not restricted to established cell lines, primary cultures were created from patients diagnosed with glioblastoma and were modestly sensitive to BKM120 or TRAIL as single agents, while the combination induced apoptosis (Fig. 2A). Statistical significance was reached when comparing single agent TRAIL treatment to combination treatment for both the established and primary lines. Human astrocytes were subjected to individual agents and co-treatment for $24 \mathrm{~h}$ and analyzed by Annexin V/PI assay; neither individual agents nor co-treatment showed significant toxicity in non-neoplastic human astrocytes (Fig. 2B). Having validated the hypothesis that inhibition of Akt signaling via BKM120 can promote TRAIL activity, we examined potential mechanisms involved, including promotion of caspase cleavage and activation of the mitochondrial apoptotic pathway.

Co-treatment of TRAIL-resistant glioma cell lines with BKM120 and TRAIL activates the caspase cascade. Western blot analysis [dose-response (Fig. 3A) and time-course 
A

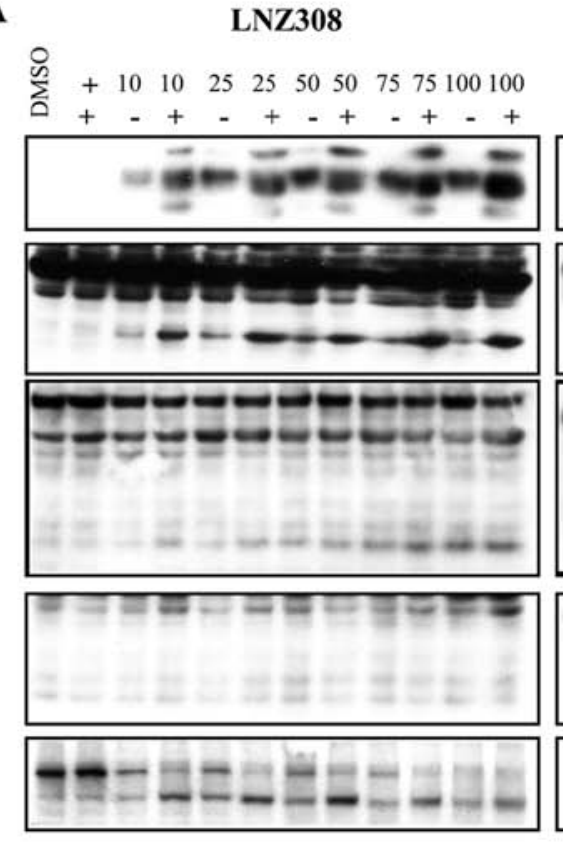

U87
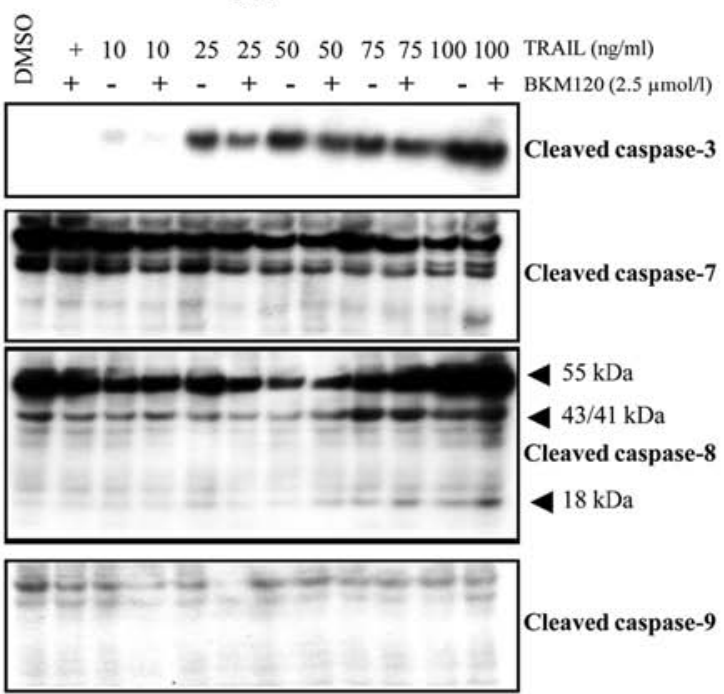

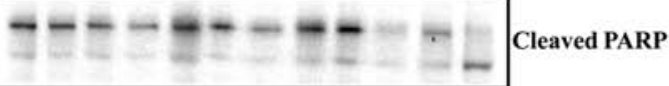

B

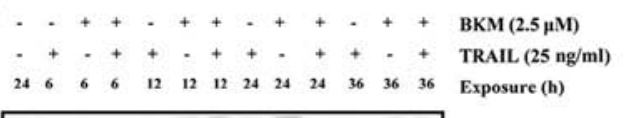

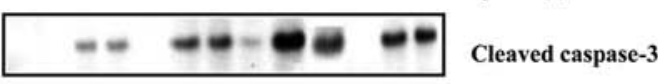
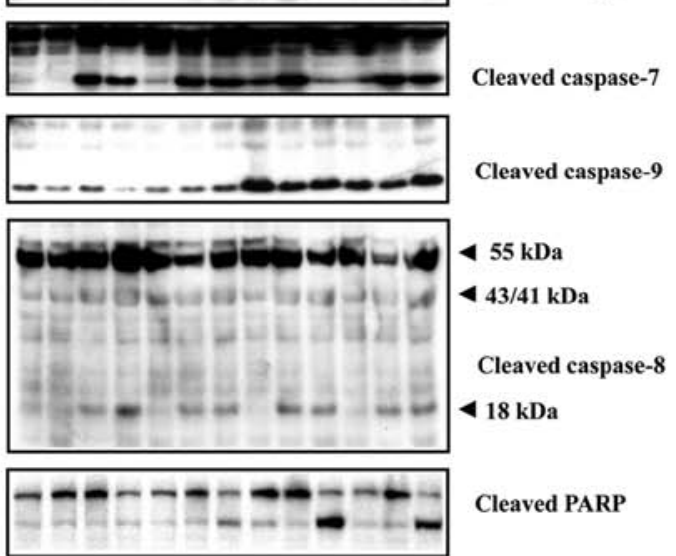

Cleaved PARP

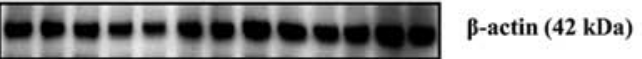

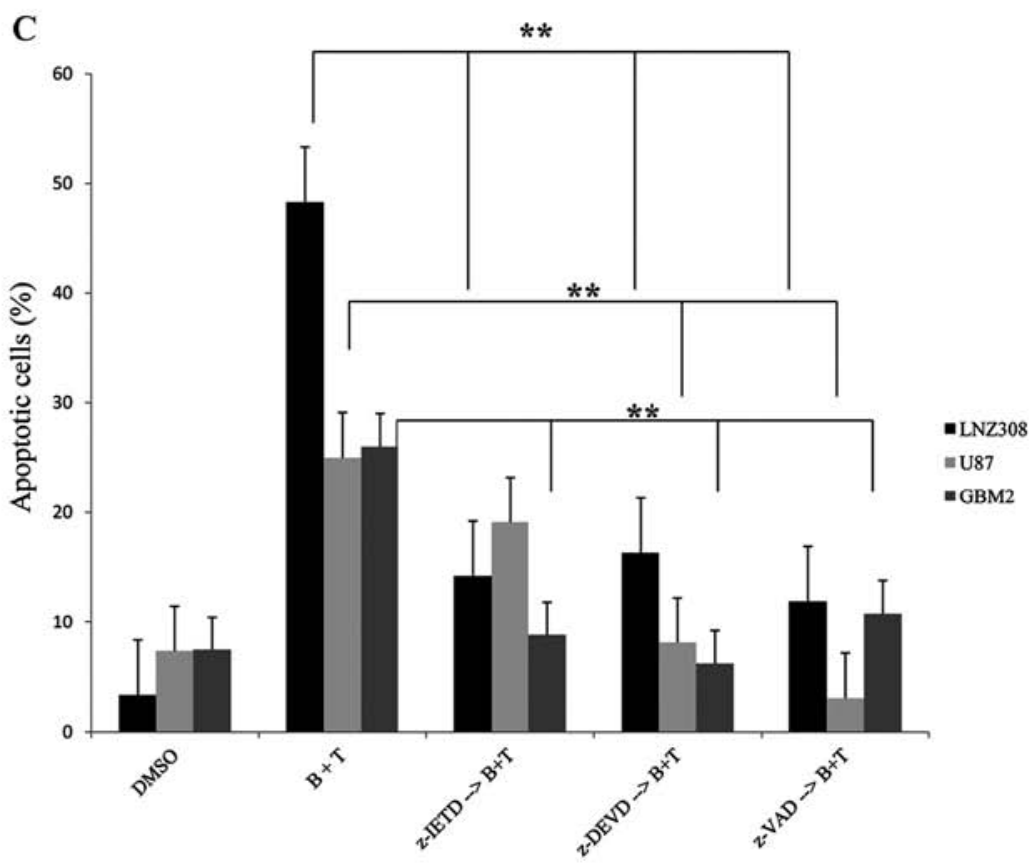

Figure 3. Cotreatment of TRAIL-resistant glioma cell lines with BKM120 and TRAIL activates the caspase cascade. (A) LNZ308 and U87 cell lines were treated with TRAIL or BKM120 or the combination of both at designated doses for $24 \mathrm{~h}$. Cell extracts were subjected to western blot analysis with indicated antibody. Arrows correlate to the molecular weights indicated in parentheses next to the name of protein and $\beta$-actin served as the loading control. (B) LNZ308 and U87 cells were treated with TRAIL or BKM120 or the combination of both for $6,12,24$ and $36 \mathrm{~h}$. Cell extracts were subjected to western blot analysis with indicated antibody. Arrows correlate to the molecular weights indicated in parentheses following the name of protein and $\beta$-actin served as loading control. (C) LNZ308 and U87 cell lines and primary patient sample (GBM 2) were pre-incubated with caspase-specific inhibitors for $2 \mathrm{~h}$ (z-DEVD-fmk, caspase-3 inhibitor; z-IETD-fmk, caspase-8 inhibitor; z-VAD-fmk, pan-caspase inhibitor) and the effect on cell death was examined with Annexin V/PI assay. Bar graph is representative of three independent experiments. Standard deviation was $<5 \%$ and error bars are shown. ${ }^{* *} \mathrm{p}<0.05$.

(Fig. 3B)] demonstrates activation of the main effector caspase- 3 more robustly with combination treatment than with treatment of TRAIL or BKM120 alone and in a timedependent manner, as early as $6 \mathrm{~h}$ in LNZ308; cleavage of PARP was seen as early as $12 \mathrm{~h}$. The initiator caspase- 8 was activated by proteolytic cleavage as shown by intermediate (43-kDa) and active (18-kDa) fragments. The downstream caspase-7 showed early cleavage in LNZ308.
As caspases appeared to have a central role in BKM120 and TRAIL-mediated apoptosis, LNZ308, U87 and primary patient GBM cells were preincubated with caspase-specific inhibitors (z-DEVD-fmk, caspase-3 inhibitor; z-IETD-fmk, caspase- 8 inhibitor; z-VAD-fmk, pan-caspase inhibitor) and the effect on cell death was examined with Annexin V/PI assay. Inhibition of caspase- 3 and use of a pan-caspase inhibitor decreased co-treatment-induced cellular death in all lines, 


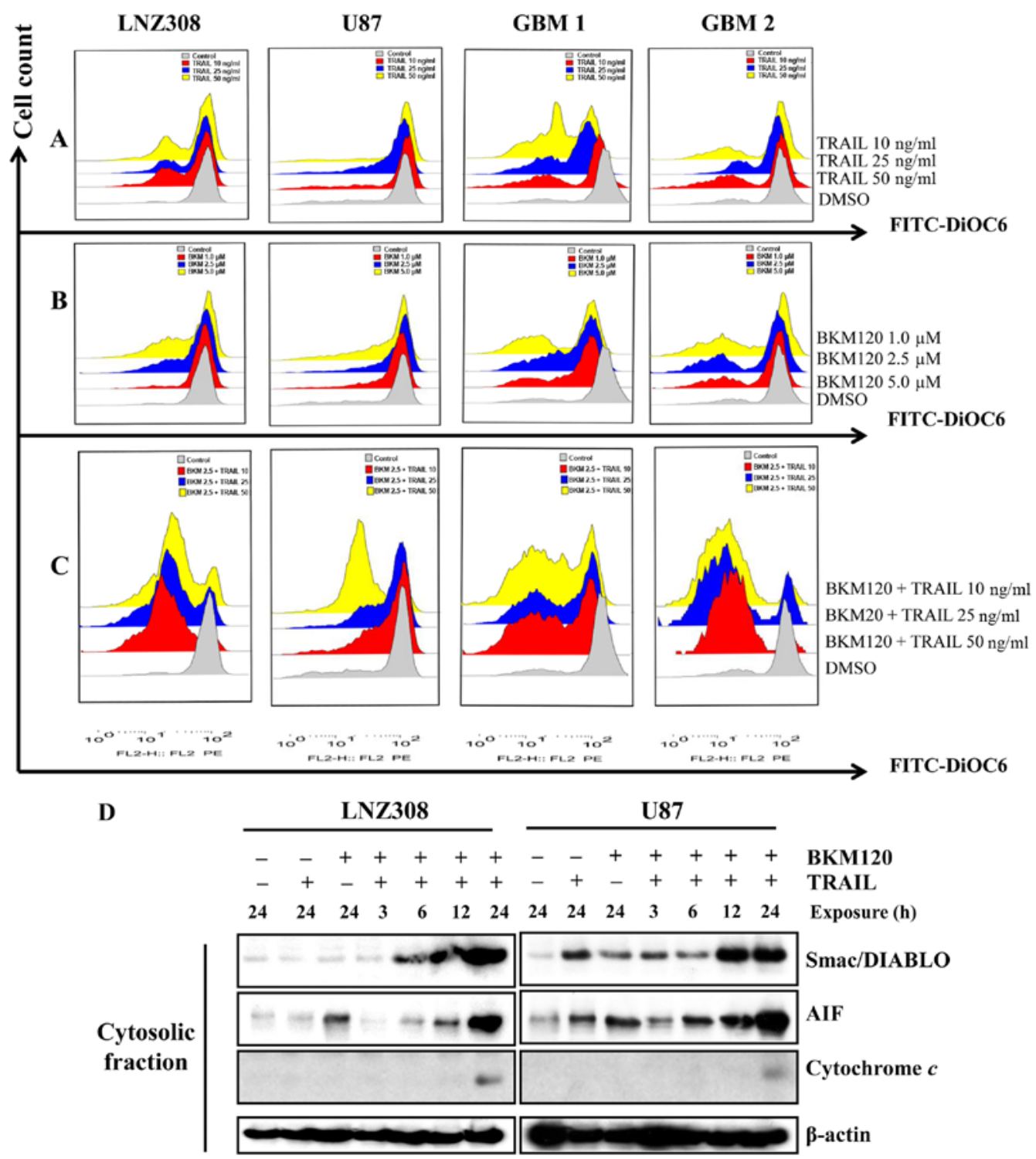

Figure 4. BKM120 and TRAIL co-treatment induces loss of mitochondrial membrane potential $(\Delta \psi \mathrm{m})$ and release of mitochondrial protein into the cytosol. Established glioma cells (LNZ308 and LN229) and primary cultures from 2 GBM patients (GBM 1 and GBM 2) were treated with the indicated concentrations of TRAIL (A), BKM120 (B) or the combination of both (with BKM120 dose of $2.5 \mu \mathrm{M}$ ) (C) for $18 \mathrm{~h}$. The integrity of the mitochondrial membranes of the cells was examined by DiOC6 staining and flow cytometry. Decrease in fluorescence intensity reflected loss of $\Delta \psi \mathrm{m}$. Data are representative of three independent experiments (D) LNZ308 and U87 cells were treated with TRAIL or BKM120 or the combination of both for the indicated duration. Cytosolic extract was prepared, and equal amounts of protein were separated by SDS-PAGE and subjected to western blot analysis with the indicated antibodies. $\beta$-actin served as loading control.

while caspase- 8 inhibition significantly diminished cell death in LNZ308 and the primary patient sample (Fig. 3C).

BKM120 and TRAIL co-treatment induces loss of mitochondrial membrane potential $(\Delta \psi m)$ and release of mitochondrial protein into the cytosol. Mitochondria play the central role in the intrinsic pathway of cellular death. Evidence suggests that loss of mitochondrial $\Delta \psi \mathrm{m}$ and release of soluble proteins, such as cytochrome c, into the cytosol are major events associated with intrinsic pathway apoptosis $(30,31)$. To evaluate if mitochondrial-related cell death played a role in combination-induced apoptosis, we utilized the DiOC6 assay. In both established and primary cells, TRAIL (Fig. 4A) and BKM120 (Fig. 4B) induced minimal loss in mitochondrial $\Delta \psi \mathrm{m}$, while co-treatment significantly increased the cellular population with loss of mitochondrial $\Delta \psi \mathrm{m}$ (Fig. $4 \mathrm{C}$ ). This result was most robustly seen in LNZ308 and the primary patient samples.

Loss of mitochondrial $\Delta \psi \mathrm{m}$ is associated with release of mitochondrial intermembrane proteins into the cytosol that are critical in activating initiator caspases. We evaluated the release of Smac/DIABLO, apoptosis-inducing factor (AIF) and cytochrome $\mathrm{c}$ and observed accumulation in the cytosolic fraction (Fig. 4D) after combination exposure. The release of Smac/ DIABLO and AIF occurred as early as $6 \mathrm{~h}$ post-treatment in both lines, while cytochrome c showed expression at $24 \mathrm{~h}$.

BKM120-induced Noxa upregulation and Noxa interaction with Mcl-1 may potentiate TRAIL toxicity. Levels of the Bcl-2 family members Mcl-1 (anti-apoptotic) and Noxa (proapoptotic), as well as their interaction, play a critical role in determining TRAIL lethality $(18,20,32-34)$. Therefore, we 
A $\quad$ LNZ308

BKM120 ( $\mu \mathrm{mol} / \mathrm{l})$

Exposure (24 h)

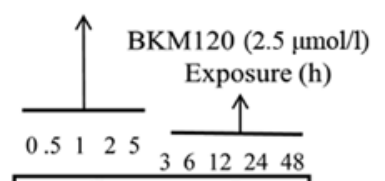

\begin{tabular}{|l|}
\hline 00 - -0000 \\
\hline \hline 000000
\end{tabular}

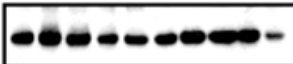

$-+\infty+\pi+\infty+\cdots$

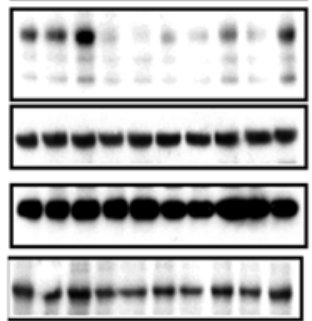

LNZ308

BKM120 ( $\mu \mathrm{mol} / \mathrm{l})$

Exposure $(24 \mathrm{~h})$
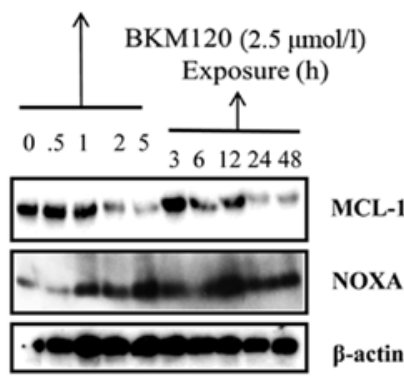

BIM

BCL-2

XIAP
U87

BKM120 ( $\mu \mathrm{mol} / \mathrm{l})$

Exposure (24 h)

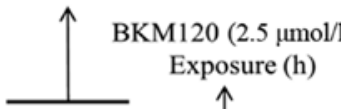

$0 . 5 1 2 5 \longdiv { 3 6 1 2 2 4 4 8 }$

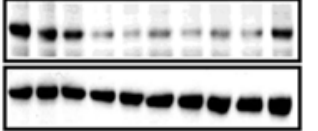

Total AKT

Phospho-S6 kinase

Phospho-BAD (S112)

BCL-xL
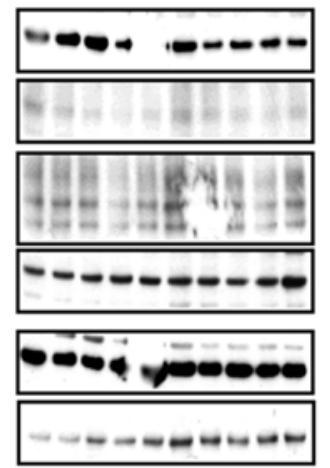

U87

BKM120 $(\mu \mathrm{mol} / \mathrm{l})$

Exposure (24 h)

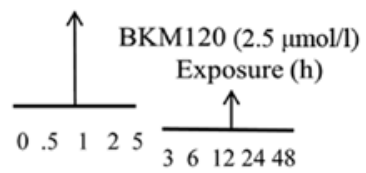

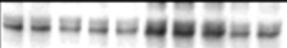

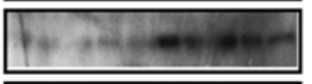

0000000

B
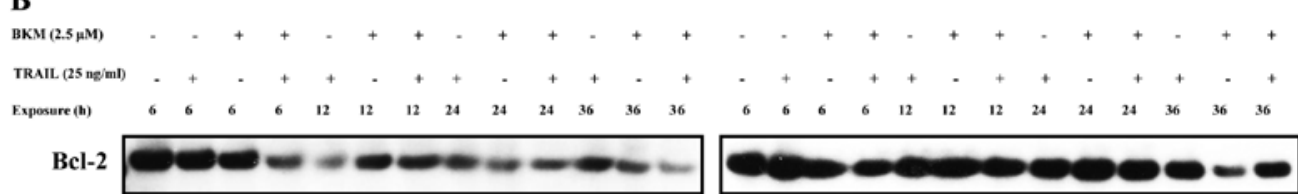

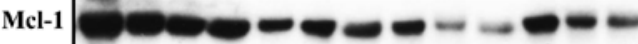
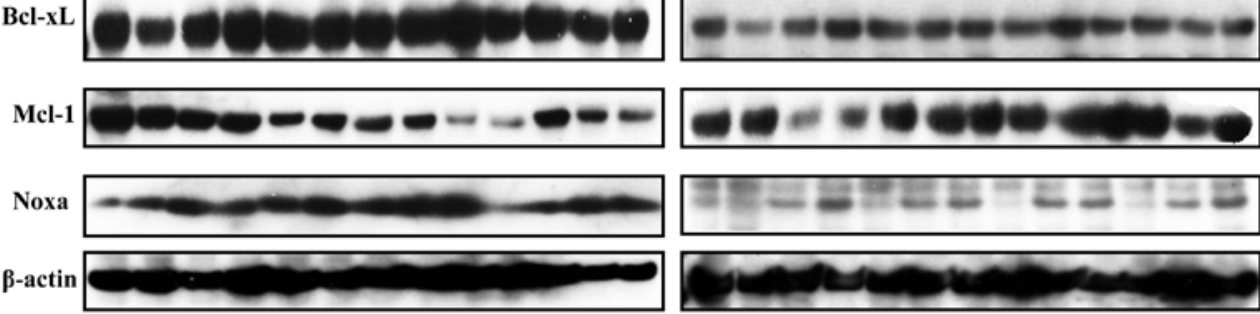

LNZ308
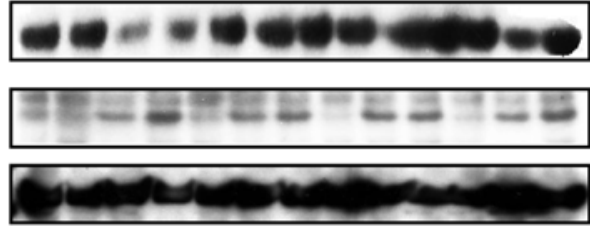

U87

Figure 5. BKM120-induced Noxa upregulation and Noxa interaction with Mcl-1 may potentiate TRAIL toxicity. (A) Cells were treated with BKM120 at indicated doses for $24 \mathrm{~h}$, as well as exposed to BKM120 $2.5 \mu \mathrm{mol} / 1$ for indicated time and examined in a time-dependent manner. Cell extracts were subjected to western blot analysis with indicated antibody. $\beta$-actin served as loading control. (B) LNZ308 and U87 cells were treated with indicated concentrations of TRAIL or BKM120 or combination of both for indicated duration. Cell extracts were subjected to western blot analysis with indicated antibody. $\beta$-actin served as loading control.

hypothesized that shifting Bcl family protein homeostasis may contribute to BKM120-TRAIL cellular death. Western blot analysis demonstrated that target inhibition occurred with
BKM120 exposure, as levels of pAKT (but not total AKT) were diminished in both lines in a time- and dose-dependent manner (Fig. 5A). We examined whether BKM120 exposure 

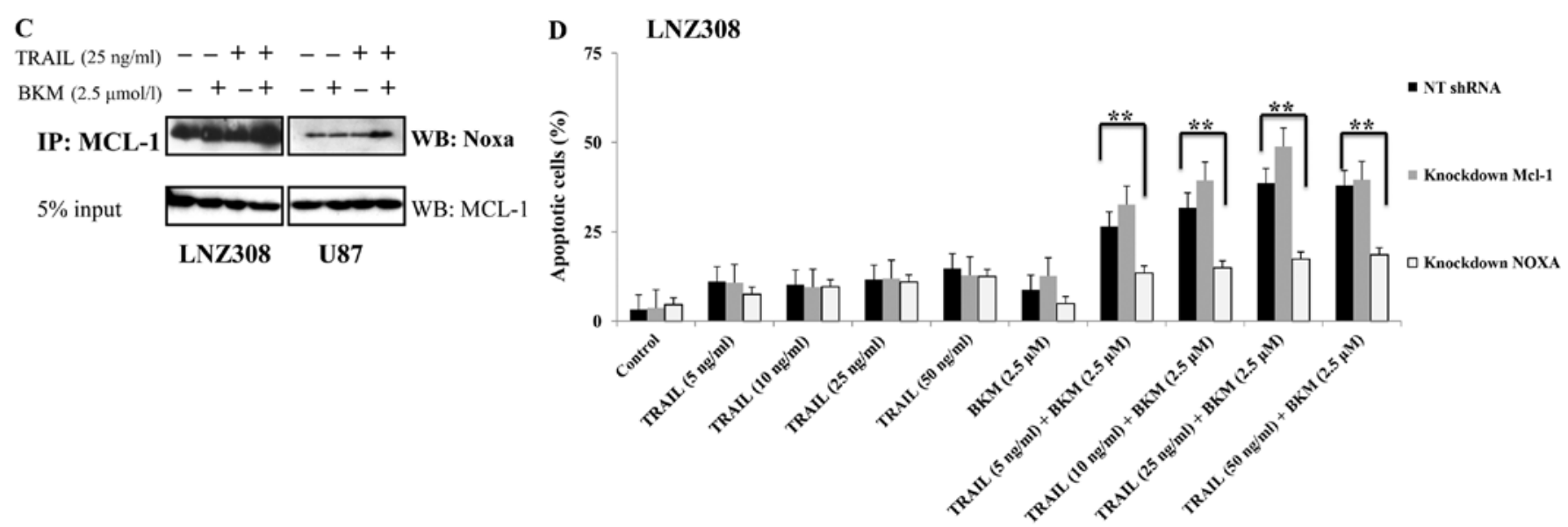

Figure 5. Continued. BKM120-induced Noxa upregulation and Noxa interaction with Mcl-1 may potentiate TRAIL toxicity. (C) LNZ308 and U87 cells were treated with indicated concentrations of TRAIL or BKM120 or combination of both for $24 \mathrm{~h}$. An equal amount of protein $(500 \mu \mathrm{g})$ was immunoprecipitated (IP) with Mcl-1 antibody and subjected to western blot analysis using the indicated antibodies. IP:Mcl-1 probed with Mcl-1 served as control (IP:Mcl-1; WB:Mcl-1). (D) LNZ308 cells were subjected to non-target (control), Noxa and Mcl-1 shRNA, as described in Materials and methods. Following transfection, cells were incubated in the presence of SAHA and ABT-737 (indicated concentration) for $24 \mathrm{~h}$. Control cells received DMSO (vehicle). At the end of the treatment period, the viable cell numbers were determined by flow cytometric analysis. The mean number of apoptotic cells acquired from two independent experiments is shown. The standard deviation was $<5 \%$ and error bars are shown. ${ }^{* *} \mathrm{p}<0.05$ values were considered statistically significant and represent the decrease in percent of apoptosis following transfection with shNoxa; shMcl-1 transfection showed a trend towards increased apoptosis compared to control (NT shRNA), but was not statistically significant.

could alter the levels of proteins known to be crucial to both the intrinsic and extrinsic apoptotic pathways, including Bcl-2 and XIAP family members.

We found little effect on expression of major Bcl-2 family proteins Bcl-2 and Bcl-xL or the IAP family member XIAP (Fig. 5A); however, we observed increased levels of Noxa, a pro-apoptotic Bcl-2 family member, and decreased levels of Mcl-1, a well-established pro-survival protein and downstream target of the Akt-signaling pathway, in a time- and dose-dependent manner (Fig. 5A). Levels of survivin, phosphorylated Bad (S112) and BIM remained unchanged (data not shown).

Next we examined expression levels in a time-dependent manner after co-treatment with TRAIL and BKM120 and again found downregulation of Mcl-1 and upregulation of Noxa, with unchanged levels of Bcl-2 and Bcl-xL (Fig. 5B). To determine if this combination alters Mcl-1:Noxa interactions, given that sequestration of the pro-survival Mcl-1 by Noxa could tip the balance to cellular death, we performed immunoprecipitation of Mcl-1 and subjected the product to western blot analysis of Noxa. The combination increased Mcl-1:Noxa association (Fig. 5C). To examine the hypothesis that Mcl-1 downregulation and Noxa upregulation are required for TRAIL-induced apoptosis, we performed RNA interference experiments to knock-down the expression of both proteins. We transiently transfected and treated cells as indicated in Fig. 5D, then analyzed cellular viability with flow cytometry. After co-treatment, a decrease in Noxa levels resulted in a statistically significant decrease in cell toxicity, while Mcl-1 knockdown showed a trend toward increased death after co-treatment.

BKM120 upregulates cell surface expression of DR5. The death receptor-induced apoptotic pathway (also called the extrinsic apoptotic pathway) is initiated by death ligands, most commonly Fas ligand (FasL), tumor necrosis factor (TNF), and TRAIL. It has been shown that Akt inhibition upregulates FasL $(35,36)$ and that PI3K inhibition can sensitize glioblastoma to death receptor-induced apoptosis (3); we hypothesized that Akt inhibition would affect expression of death receptors. In our study, BMK120 treatment produced an increase in the expression of DR5, with evidence of protein expression at $1 \mu \mathrm{mol} / 1$ at $24 \mathrm{~h}$ post-treatment. There was no change in the expression levels of DR4 or decoy receptor 1 (DcR1) in either cell line (Fig. 6A). In a time-dependent manner, BKM120 alone and combination treatment produced increased levels of DR5 in both lines as early as $6 \mathrm{~h}$, but no time-dependent change in expression of DR4 or DcR1 was observed. FACS analysis showed that the cell surface expression of DR5 was increased in LNZ308 and U87 cell lines treated with BKM120, without a change in the expression of DR4 (Fig. 6B).

\section{Discussion}

Drug resistance remains a major barrier for cancer therapeutics and multiple pathways contribute to cell death resistance in glioma. Currently, there is great interest in aberrant PI3K/Akt signaling in glioma and increased activity of this pathway may be responsible for the dismal prognosis associated with glioblastoma (37). While many human cancer cells express death receptors, various cancer types, including some glioma cell lines, remain resistant to TRAIL. Akt pathway activation, a frequent finding in human glioma, correlates with TRAIL resistance. Studies have shown that inhibition of PI3K/Akt pathway with siRNA or small molecule inhibitors can sensitize cancer cells to TRAIL $(3,20,28,38)$. The efficacy of PI3K/Akt/mTOR pathway inhibitors in combination with TRAIL has been previously demonstrated $(28,39,40)$, while the effect of BKM120 and TRAIL co-treatment has not been examined in glioma.

In our study, both the extrinsic and intrinsic pathways of cellular death are implicated. As monotherapy, neither TRAIL 
A $\operatorname{BKM120}(\mu \mathrm{mol} / \mathrm{l})$

Exposure (24 h)

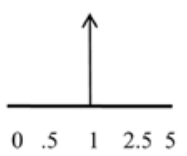

$-\quad++-++-++\operatorname{BKM}(2.5 \mu \mathrm{M})$

$\begin{array}{lllll}0 & .5 & 1 & 2.5 & 5\end{array}$

$\begin{array}{lllllllllll}6 & 6 & 6 & 6 & 12 & 12 & 12 & 24 & 24 & 24 & \text { Exposure }(\mathrm{h})\end{array}$
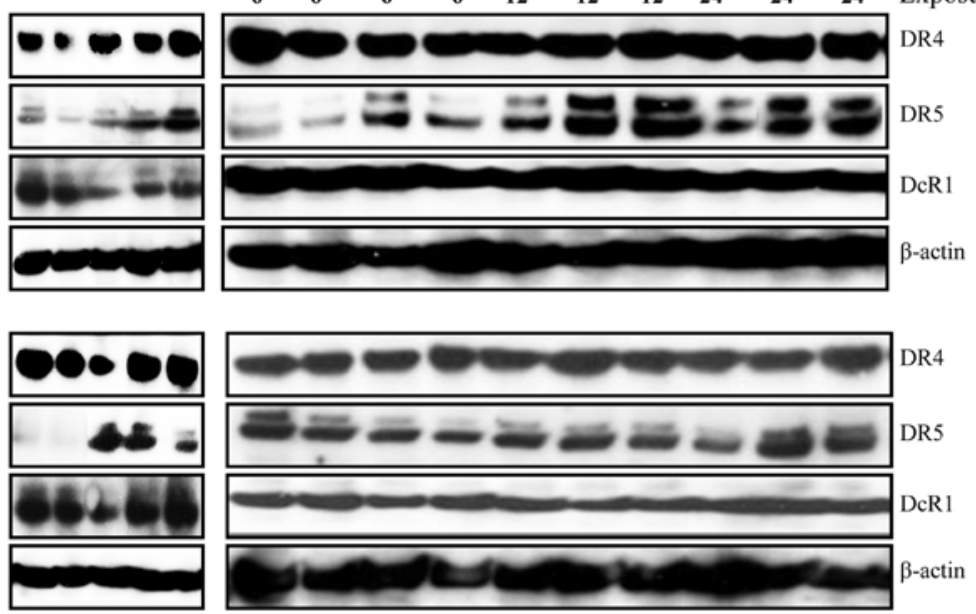

LNZ308

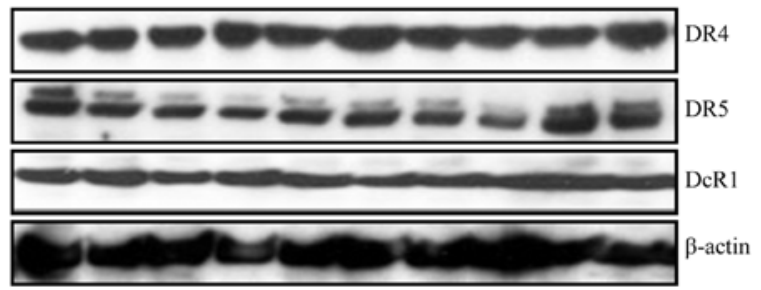

B
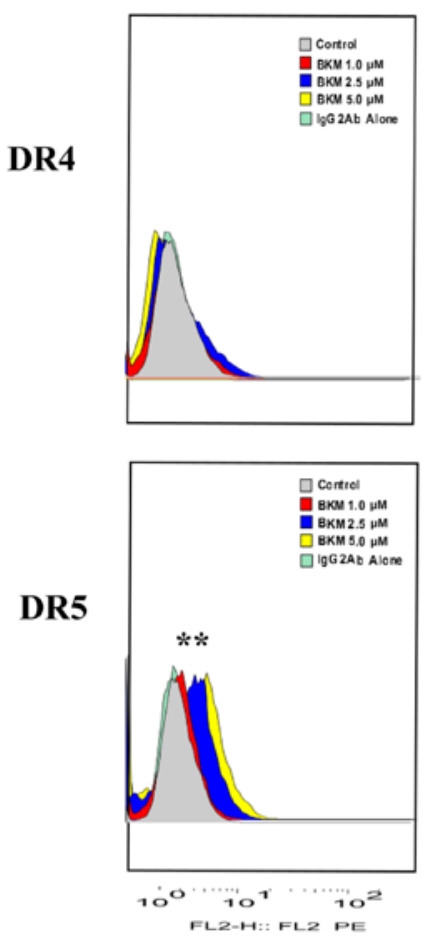

U87
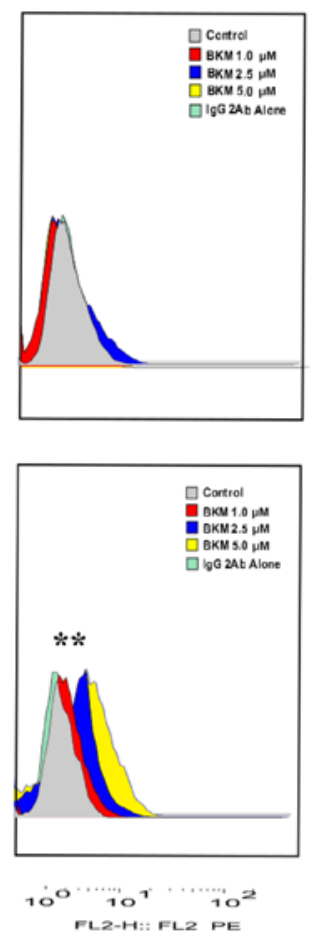

Figure 6. BKM120 upregulates cell surface expression of DR5. (A) Cells were treated with BKM120 at indicated doses for $24 \mathrm{~h}$, as well as exposed to TRAIL $(25 \mathrm{ng} / \mathrm{ml})$ or BKM120 $(2.5 \mu \mathrm{M})$ or combination for the indicated time and examined in a time-dependent manner. Cell extracts were subjected to western blot analysis with the indicated antibody. $\beta$-actin served as loading control. (B) Cells were treated with BKM120 in mono-treatment at indicated doses for $24 \mathrm{~h}$ Cell surface expression of death receptors was analyzed by flow cytometry. Images are representative of data from 3 independent experiments. ${ }^{* *} \mathrm{p}<0.05$ values considered statistically significant, representing the difference between control and BKM120 at $2.5 \mu \mathrm{M}$.

nor BKM120 demonstrated a robust change in the mitochondrial $\Delta \psi \mathrm{m}$, while the combination induced loss of mitochondrial $\Delta \psi \mathrm{m}$. Moreover, analysis of the cytosolic fraction demonstrated the presence of Smac/DIABLO, AIF and cytochrome c, all critical players in the intrinsic pathway. Regulation of the mitochondrial pathway occurs via an intricate balance between expression levels of pro-apoptotic and pro-survival members of the Bcl-2 family, and levels of two proteins in this family, Mcl-1 and Noxa, appear critical.

It is well-established that Mcl-1, a known downstream regulator of the PI3K/Akt pathway, plays a prominent role in the inhibition of apoptosis, while Noxa is crucial in facilitating apoptosis; cellular death following co-treatment may be more contingent on levels of Noxa than Mcl-1. In this regard, we 
observed significant upregulation of the pro-apoptotic mediator Noxa associated with sequestration of the anti-apoptotic mediator Mcl-1, without significant changes in other Bcl-2 family members, suggesting the important role of these targets in regulating the responses observed. While it has been reported that TRAIL actually increases levels of the pro-survival protein Mcl-1, likely contributing to TRAIL resistance, studies have shown that a second agent that can reduce Mcl-1 levels could serve as effective co-treatment (14).

After knock-down of Mcl-1, we did not observe a statistically significant increase in the amount of cell death from control. On the other hand, western blot analysis showed an increase in the levels of Noxa after treatment with BKM120 alone and co-treatment. As shown by immunoprecipitation, Noxa sequestered Mcl-1, suggesting that levels of the proapoptotic protein Noxa may be more critical to the mechanism of cellular death than Mcl-1. shRNA experiments demonstrated that the loss of expression of Noxa limited the ability of this combination to produce cell death. In short, Noxa upregulation may post-transcriptionally inactivate Mcl-1 and allow for displacement of other pro-apoptotic proteins bound to Mcl-1 $(41,42)$.

Our study showed an increase in total death receptor protein levels and death receptor expression at the cellular membrane, specifically DR5 and not DR4, after treatment with BKM120. Since TRAIL triggers apoptosis by binding DR4 and DR5, the expression of death receptors may be pivotal in determining the apoptotic response to death receptor-mediated cell death (43). Multiple recent studies have shown that the upregulation of death receptors, in particular DR5, by other agents such as proteosome inhibitors (44), amiodorone (45), arsenic trioxide (46), and platinum-based chemotherapies (47), can sensitize TRAIL-resistant glioma cell lines to TRAIL-induced cellular death and the use of sensitizers that can upregulate DR5 expression may allow for the selective death of glioma, sparing normal human astrocytes. Recently, an intimate connection has been shown to exist between diminished Akt pathway activation and an increase in DR5 expression (48). Nonetheless, a study evaluating co-treatment with BKM120 and TRAIL in lung cancer cell lines, at the same doses as used in our study, examined levels of DR4 and DR5 after treatment with BKM120 for $16 \mathrm{~h}$ and saw no change in receptor levels (in fact, a decrease in DR4 levels) (28), in contrast to the clear increase in DR5 expression we observed in human glioma. The mechanism by which PI3K/Akt pathway inhibition may lead to DR5 upregulation remains to be elucidated. The effect of PI3K/ Akt pathway inhibition on the expression of death receptors deserves further examination and future studies looking at this combination should consider evaluation of extrinsic pathway proteins.

This study demonstrates that BKM120 augments TRAILinduced apoptosis in proven TRAIL-resistant glioma cell lines. The combination shows efficacy in primary patient samples and no evidence of significant cellular death in normal human astrocytes. While Mcl-1 is downregulated by combination treatment, it appears that increased levels of Noxa are critical to cellular death in glioma. Moreover, treatment of TRAILresistant glioma cells with BKM120 increases expression of DR5, but not DR4, in both the intracellular milieu and at the cell surface. Our findings suggest further investigation of this combination in vivo is warranted.

\section{Acknowledgements}

This work was supported by National Institutes of Health Grant P01NS40923 (I.F.P.), by the Walter L. Copeland of The Pittsburgh Foundation (K.A.F., D.R.P.), and grants from the Ian's Friends Foundation (to I.F.P.) in honor of Ian Yagoda, and the Children's Hospital of Pittsburgh Foundation (to I.F.P.).

\section{References}

1. Maher EA, Furnari FB, Bachoo RM, Rowitch DH, Louis DN, Cavenee WK and DePinho RA: Malignant glioma: Genetics and biology of a grave matter. Genes Dev 15: 1311-1333, 2001

2. Wen PY and Kesari S: Malignant gliomas in adults. N Engl J Med 359: 492-507, 2008.

3. Opel D, Westhoff MA, Bender A, Braun V, Debatin KM and Fulda S: Phosphatidylinositol 3-kinase inhibition broadly sensitizes glioblastoma cells to death receptor- and drug-induced apoptosis. Cancer Res 68: 6271-6280, 2008.

4. Pollack IF, Jakacki RI, Blaney SM, Hancock ML, Kieran MW, Phillips P, Kun LE, Friedman H, Packer R, Banerjee A, et al: Phase I trial of imatinib in children with newly diagnosed brainstem and recurrent malignant gliomas: A Pediatric Brain Tumor Consortium report. Neuro Oncol 9: 145-160, 2007.

5. Prados MD, Chang SM, Butowski N, DeBoer R, Parvataneni R, Carliner H, Kabuubi P, Ayers-Ringler J, Rabbitt J, Page M, et al: Phase II study of erlotinib plus temozolomide during and after radiation therapy in patients with newly diagnosed glioblastoma multiforme or gliosarcoma. J Clin Oncol 27: 579-584, 2009.

6. Omuro AM, Faivre S and Raymond E: Lessons learned in the development of targeted therapy for malignant gliomas. Mol Cancer Ther 6: 1909-1919, 2007.

7. Hanahan D and Weinberg RA: Hallmarks of cancer: The next generation. Cell 144: 646-674, 2011.

8. Kelley SK and Ashkenazi A: Targeting death receptors in cancer with Apo2L/TRAIL. Curr Opin Pharmacol 4: 333-339, 2004.

9. Bellail AC, Qi L, Mulligan P, Chhabra V and Hao C: TRAIL agonists on clinical trials for cancer therapy: The promises and the challenges. Rev Recent Clin Trials 4: 34-41, 2009.

10. Hall MA and Cleveland JL: Clearing the TRAIL for cancer therapy. Cancer Cell 12: 4-6, 2007.

11. von Pawel J, Harvey JH, Spigel DR, Dediu M, Reck M, Cebotaru CL, Humphreys RC, Gribbin MJ, Fox NL and Camidge DR: Phase II trial of mapatumumab, a fully human agonist monoclonal antibody to tumor necrosis factor-related apoptosis-inducing ligand receptor 1 (TRAIL-R1), in combination with paclitaxel and carboplatin in patients with advanced non-small-cell lung cancer. Clin Lung Cancer 15: 188-196.e2, 2014.

12. Forero-Torres A, Infante JR, Waterhouse D, Wong L, Vickers S, Arrowsmith E, He AR, Hart L, Trent D, Wade J, et al: Phase 2, multicenter, open-label study of tigatuzumab (CS-1008), a humanized monoclonal antibody targeting death receptor 5 , in combination with gemcitabine in chemotherapy-naive patients with unresectable or metastatic pancreatic cancer. Cancer Med 2: 925-932, 2013.

13. Takeda K, Stagg J, Yagita H, Okumura K and Smyth MJ: Targeting death-inducing receptors in cancer therapy. Oncogene 26: 3745-3757, 2007.

14. Zhang L and Fang B: Mechanisms of resistance to TRAILinduced apoptosis in cancer. Cancer Gene Ther 12: 228-237, 2005.

15. Russo M, Mupo A, Spagnuolo C and Russo GL: Exploring death receptor pathways as selective targets in cancer therapy. Biochem Pharmacol 80: 674-682, 2010.

16. Yang A, Wilson NS and Ashkenazi A: Proapoptotic DR4 and DR5 signaling in cancer cells: Toward clinical translation. Curr Opin Cell Biol 22: 837-844, 2010.

17. Kim EH, Kim HS, Kim SU, Noh EJ, Lee JS and Choi KS: Sodium butyrate sensitizes human glioma cells to TRAIL-mediated apoptosis through inhibition of Cdc2 and the subsequent downregulation of survivin and XIAP. Oncogene 24: 6877-6889, 2005. 
18. Premkumar DR, Jane EP, Foster KA and Pollack IF: Survivin inhibitor YM-155 sensitizes tumor necrosis factor-related apoptosis-inducing ligand-resistant glioma cells to apoptosis through Mcl-1 downregulation and by engaging the mitochondrial death pathway. J Pharmacol Exp Ther 346: 201-210, 2013.

19. Jane EP, Premkumar DR and Pollack IF: Bortezomib sensitizes malignant human glioma cells to TRAIL, mediated by inhibition of the NF-\{kappa\}B signaling pathway. Mol Cancer Ther 10: 198-208, 2011.

20. Opel D, Naumann I, Schneider M, Bertele D, Debatin KM and Fulda S: Targeting aberrant PI3K/Akt activation by PI103 restores sensitivity to TRAIL-induced apoptosis in neuroblastoma. Clin Cancer Res 17: 3233-3247, 2011.

21. Okhrimenko H, Lu W, Xiang C, Hamburger N, Kazimirsky G and Brodie C: Protein kinase $\mathrm{C}$-epsilon regulates the apoptosis and survival of glioma cells. Cancer Res 65: 7301-7309, 2005.

22. Salmena L, Carracedo A and Pandolfi PP: Tenets of PTEN tumor suppression. Cell 133: 403-414, 2008.

23. Maira SM, Pecchi S, Huang A, Burger M, Knapp M, Sterker D, Schnell C, Guthy D, Nagel T, Wiesmann M, et al: Identification and characterization of NVP-BKM120, an orally available pan-class I PI3-kinase inhibitor. Mol Cancer Ther 11: 317-328, 2012

24. Zheng Y, Yang J, Qian J, Zhang L, Lu Y, Li H, Lin H, Lan Y, Liu Z, He J, et al: Novel phosphatidylinositol 3-kinase inhibitor NVP-BKM120 induces apoptosis in myeloma cells and shows synergistic anti-myeloma activity with dexamethasone. J Mol Med Berl 90: 695-706, 2012.

25. Koul D, Fu J, Shen R, LaFortune TA, Wang S, Tiao N, Kim YW, Liu JL, Ramnarian D, Yuan Y, et al: Antitumor activity of NVP-BKM120 - a selective pan class I PI3 kinase inhibitor showed differential forms of cell death based on p53 status of glioma cells. Clin Cancer Res 18: 184-195, 2012.

26. Brachmann SM, Kleylein-Sohn J, Gaulis S, Kauffmann A, Blommers MJ, Kazic-Legueux M, Laborde L, Hattenberger M, Stauffer F, Vaxelaire J, et al: Characterization of the mechanism of action of the pan class I PI3K inhibitor NVP-BKM120 across a broad range of concentrations. Mol Cancer Ther 11: 1747-1757, 2012.

27. Bendell JC, Rodon J, Burris HA, de Jonge M, Verweij J, Birle D, Demanse D, De Buck SS, Ru QC, Peters M, et al: Phase I, doseescalation study of BKM120, an oral pan-Class I PI3K inhibitor, in patients with advanced solid tumors. J Clin Oncol 30: 282-290, 2012.

28. Ren H, Zhao L, Li Y, Yue P, Deng X, Owonikoko TK, Chen M, Khuri FR and Sun SY: The PI3 kinase inhibitor NVP-BKM120 induces GSK3/FBXW7-dependent Mcl-1 degradation, contributing to induction of apoptosis and enhancement of TRAIL-induced apoptosis. Cancer Lett 338: 229-238, 2013.

29. Premkumar DR, Jane EP, DiDomenico JD, Vukmer NA Agostino NR and Pollack IF: ABT-737 synergizes with bortezomib to induce apoptosis, mediated by Bid cleavage, Bax activation, and mitochondrial dysfunction in an Akt-dependent context in malignant human glioma cell lines. J Pharmacol Exp Ther 341: 859-872, 2012.

30. Jane EP, Premkumar DR, DiDomenico JD, Hu B, Cheng SY and Pollack IF: YM-155 potentiates the effect of ABT-737 in malignant human glioma cells via survivin and Mcl-1 downregulation in an EGFR-dependent context. Mol Cancer Ther 12: 326-338, 2013

31. Tait SW and Green DR: Mitochondria and cell death: Outer membrane permeabilization and beyond. Nat Rev Mol Cell Biol 11: 621-632, 2010

32. Kim SH, Ricci MS and El-Deiry WS: Mcl-1: A gateway to TRAIL sensitization. Cancer Res 68: 2062-2064, 2008.

33. Ricci MS, Kim SH, Ogi K, Plastaras JP, Ling J, Wang W, Jin Z, Liu YY, Dicker DT, Chiao PJ, et al: Reduction of TRAIL-induced Mcl-1 and cIAP2 by c-Myc or sorafenib sensitizes resistant human cancer cells to TRAIL-induced death. Cancer Cell 12: 66-80, 2007.
34. Naumann I, Kappler R, von Schweinitz D, Debatin KM and Fulda S: Bortezomib primes neuroblastoma cells for TRAIL-induced apoptosis by linking the death receptor to the mitochondrial pathway. Clin Cancer Res 17: 3204-3218, 2011.

35. Suhara T, Kim HS, Kirshenbaum LA and Walsh K: Suppression of Akt signaling induces Fas ligand expression: Involvement of caspase and Jun kinase activation in Akt-mediated Fas ligand regulation. Mol Cell Biol 22: 680-691, 2002.

36. Uriarte SM, Joshi-Barve S, Song Z, Sahoo R, Gobejishvili L, Jala VR, Haribabu B, McClain C and Barve S: Akt inhibition upregulates FasL, downregulates c-FLIPs and induces caspase8-dependent cell death in Jurkat T lymphocytes. Cell Death Differ 12: 233-242, 2005

37. Chakravarti A, Zhai G, Suzuki Y, Sarkesh S, Black PM, Muzikansky A and Loeffler JS: The prognostic significance of phosphatidylinositol 3-kinase pathway activation in human gliomas. J Clin Oncol 22: 1926-1933, 2004.

38. Rychahou PG, Murillo CA and Evers BM: Targeted RNA interference of PI3K pathway components sensitizes colon cancer cells to TNF-related apoptosis-inducing ligand (TRAIL). Surgery 138: 391-397, 2005.

39. Kim S, Kang J, Qiao J, Thomas RP, Evers BM and Chung DH: Phosphatidylinositol 3-kinase inhibition down-regulates survivin and facilitates TRAIL-mediated apoptosis in neuroblastomas. J Pediatr Surg 39: 516-521, 2004

40. Bagci-Onder T, Wakimoto $\mathrm{H}$, Anderegg M, Cameron $\mathrm{C}$ and Shah K: A dual PI3K/mTOR inhibitor, PI-103, cooperates with stem cell-delivered TRAIL in experimental glioma models. Cancer Res 71: 154-163, 2011.

41. Chen L, Willis SN, Wei A, Smith BJ, Fletcher JI, Hinds MG, Colman PM, Day CL, Adams JM and Huang DC: Differential targeting of prosurvival Bcl-2 proteins by their $\mathrm{BH} 3$-only ligands allows complementary apoptotic function. Mol Cell 17: 393-403, 2005.

42. Okumura K, Huang $S$ and Sinicrope FA: Induction of Noxa sensitizes human colorectal cancer cells expressing Mcl-1 to the small-molecule Bcl-2/Bcl-xL inhibitor, ABT-737. Clin Cancer Res 14: 8132-8142, 2008.

43. Kischkel FC, Lawrence DA, Chuntharapai A, Schow P, Kim KJ and Ashkenazi A: Apo2L/TRAIL-dependent recruitment of endogenous FADD and caspase- 8 to death receptors 4 and 5. Immunity 12: 611-620, 2000.

44. Seol DW: p53-Independent up-regulation of a TRAIL receptor DR5 by proteasome inhibitors: A mechanism for proteasome inhibitor-enhanced TRAIL-induced apoptosis. Biochem Biophys Res Commun 416: 222-225, 2011.

45. Kim IY, Kang YJ, Yoon MJ, Kim EH, Kim SU, Kwon TK, Kim IA and Choi KS: Amiodarone sensitizes human glioma cells but not astrocytes to TRAIL-induced apoptosis via CHOPmediated DR5 upregulation. Neuro Oncol 13: 267-279, 2011.

46. Kim EH, Yoon MJ, Kim SU, Kwon TK, Sohn S and Choi KS: Arsenic trioxide sensitizes human glioma cells, but not normal astrocytes, to TRAIL-induced apoptosis via CCAAT/ enhancer-binding protein homologous protein-dependent DR5 up-regulation. Cancer Res 68: 266-275, 2008.

47. Ding L, Yuan C, Wei F, Wang G, Zhang J, Bellail AC, Zhang Z, Olson JJ and Hao C: Cisplatin restores TRAIL apoptotic pathway in glioblastoma-derived stem cells through up-regulation of DR5 and down-regulation of c-FLIP. Cancer Invest 29: 511-520, 2011

48. Wang J, Xu F, Zhu D, Duan Y, Chen J, Sun X, He X, Li P, Sun W and Feng J: Schistosoma japonicum soluble egg antigens facilitate hepatic stellate cell apoptosis by downregulating Akt expression and upregulating p53 and DR5 expression. PLoS Negl Trop Dis 8: e3106, 2014. 